\title{
EFECTO TÓXICO DE Acremonium zeae EN POLLOS DE ENGORDA EN INICIACIÓN ${ }^{1}$
}

\author{
Alma Sánchez-Bautista ${ }^{2}$,Carlos De León García-de Alba ${ }^{2}$,Juan Manuel Cuca-García ${ }^{2}$, \\ Ana María Hernández-Anguiano ${ }^{2}$
}

\section{RESUMEN}

Efecto tóxico de Acremonium zeae en pollos de engorda en iniciación. El objetivo de este trabajo fue determinar si Acremonium zeae afecta el desarrollo de pollos de engorde. En el Colegio de Postgraduados, Campus Monteci1lo, en el Estado de México de agosto a diciembre de 2010 se realizó un experimento con pollos recién nacidos bajo un diseño experimental completamente al azar con cinco dietas (tratamientos) y cinco repeticiones, cada una constó de cinco pollos. Los animales fueron alimentados durante tres semanas con cada una de las dietas, en las que se adicionaron porcentajes de avena contaminada con $A$. zeae en sustitución del maíz. Los tratamientos fueron: T1, $0 \%$ avena contaminada: $100 \%$ de maíz; T2, 25\% avena contaminada: 75\% de maíz; T3, 50\% avena contaminada: 50\% de maíz; T4, 75\% avena contaminada: $25 \%$ de maíz; y, T5, 100\% avena contaminada: $0 \%$ de maíz. Durante tres semanas cada siete días se registró el incremento en peso de los pollos y el consumo de alimento. Hubo efecto negativo en el peso a partir de la segunda semana de alimentación, con una composición de dieta elaborada con un mínimo de 50\% de avena contaminada con el hongo.

Palabras clave: Micotoxinas, consumo de alimento, avena contaminada.

\begin{abstract}
Toxic effect of Acremonium zeae on chicken in initiation. The objective os this work was to determine if Acremonium zeae affects the develpment of chicks. The study was condducted at the Colegio de Postgraduados, Campus Montecillo, the State of Mexico, from August to December, 2010. Hatchlings were used for the experiment under a totallyrandom design with five diets (treatments) and five repetitions, each repetition with five chicks. The animals were fed for three weeks with each of the diets with different percentages of added oatmeal, contaminated with A. zeae, and mixed with corn to cover the nutritional requirements of chicken in initiation. The treatments were: T1,0\% contaminated oatmeal: $100 \%$ corn, (control); T2, 25\% contaminated oatmeal: $75 \%$ corn; T3, 50\% contaminated oatmeal: $50 \%$ corn; T4, 75\% contaminated oatmeal: $25 \%$ corn; and, T5, $100 \%$ contaminated oatmeal: $0 \%$ corn. The chickens were measured for weight gain and food intake every seven days for three weeks. The statistical analysis shows that the negative effect on weight gain and food intake is more evident from the second week of feeding with a diet composition of minimum $50 \%$ oatmeal contaminated with the fungus.
\end{abstract}

Key words: Mycotoxins, food intake, contaminated oatmeal

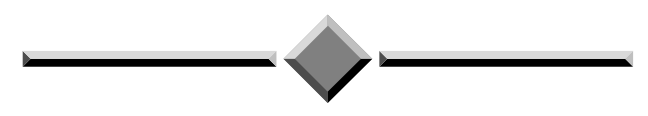

\footnotetext{
Recibido: 12 de mayo, 2011. Aceptado: 10 de enero, 2012.

2 Postgrado de Fitosanidad, zancheza@gmail.com y Colegio de Postgraduados, cdeleon@colpos.mx, jmcuca@colpos.mx, ahernandez@ colpos.mx Campus Montecillo. Carretera México-Texcoco Km.36.5. C.P. 56230 Montecillo, Texcoco, Estado de México.
} 


\section{INTRODUCCIÓN}

La mayor cantidad de la producción mundial de maíz se usa en la alimentación animal de aves de corral, cerdos, bovinos y equinos (Carvajal y De León 2010). En México existen factores que afectan su producción en las regiones tropicales, donde es dañado por un gran número de patógenos que causan daños económicos importantes. Dentro de las principales enfermedades causadas por hongos que afectan el cultivo del maíz están tizones foliares, mildius, pudriciones de caña y mazorca, manchas foliares, marchitez, carbones y royas (CIMMYT 2004), siendo de especial importancia las pudriciones de tallo causadas por $\mathrm{Fu}$ sarium y Botryodiplodia, así como las pudriciones de mazorca causadas por varias especies de los géneros Aspergillus, Fusarium, Nigrospora y Acremonium (sin. Cephalosporium).

Los hongos no solo reducen el valor nutritivo de los granos por la degradación de proteínas, grasas, carbohidratos y vitaminas (Carvajal y De León 2010). Sino también la calidad sanitaria de los mismos al formar metabolitos secundarios conocidos como micotoxinas que dañan o matan a los animales (Duarte y Villamil 2006). Se estima que el $25 \%$ de la producción mundial de cereales se encuentra contaminada con micotoxinas (Duarte y Villamil 2006), entre las que se encuentran las aflatoxinas, los tricoticenos, la ocratoxina A, las fumonisinas y la zearalenona producidas por algunos géneros como Aspergillus spp., Penicillium spp. y Fusarium spp. (CAST 2003, Cuca et al. 2009).

Algunos de los efectos que pueden observarse en aves por la presencia de micotoxinas en el alimento son: a) reducción del consumo y peso de aves, b) alteración en el contenido de nutrientes del alimento, absorción y metabolismo de los nutrientes, c) efectos en los sistemas endocrinos y exócrinos, d) supresión de las funciones del sistema inmune y e) muerte celular (Whitlow y Hagler 2005, Cuca et al. 2009).

Existen especies de Acremonium consideradas importantes productoras de toxinas en forrajes, ya que llegan a producir alcaloides similares a los producidos por Claviceps spp. (Towers y Siegel 1993). Galdames (1995), indica que existen especies de Acremonium que producen diversos metabolitos, algunos de los cuales se consideran responsables de causar intoxicación animal como es el caso del denominado temblor de ballicas o "ryegrass staggers", reportado en Nueva Zelanda donde el ballico perenne es la principal gramínea forrajera, detectando un $90 \%$ de las praderas infectadas con Acremonium lolii (Siegel et al. 1985).

Por otra parte varios compuestos producidos por endofiticos del género Acremonium son principalmente alcaloides del tipo ergopeptinas, los cuales se encuentran en concentraciones variables y han sido determinados en las asociaciones de endofiticos con la Ballica y Festuca, así como en cultivos puros de algunos de los hongos, a los que se considera principales responsables de los problemas de toxicidad animal (Scott $e t$ al. 1999).

El endofitico de la Festuca fue inicialmente clasificado como Sphacelia typhina Sacc., la forma anamórfica o asexual de Ephicloë typhina (Pers.) Tul. Posteriormente, Morgan-Jones y Gams, renombran a Sphacelia como Acremonium y lo llama finalmente Acremonium coenophialum (Morgan-Jones y Gams 1982). Siguiendo este mismo esquema, Latch et al. (1984), clasifican al endofitico del ballico como Acremonium lolii.

El término alcaloide fue acuñado por el farmacéutico W. Meissner en 1819 y se aplica a metabolitos secundarios alcalinos que contienen nitrógeno (Gros et al. 1985). La presencia de alcaloides en Poaceae se debe a simbiontes fúngicos asociados parásitos (Claviceps y Balansia) y a endófitos fúngicos mutualistas (Neotyphodium) (Chapman, 1996). Neotyphodium llega a producir alcaloides del tipo de lolitrem B, ergovalina y peramina, entre otros (Spiering et al. 2005).

El hongo deuteromiceto Neotyphodium coenophialum (sin. Acremonium coenophialum) (Glenn et al. 1996, Morgan-Jones y Gams 1982) infecta sistémicamente plantas de Festuca arundinacea. El micelio invade el espacio intercelular en las plantas sin que éstas presenten ningún síntoma externo. $N$. coenophialum es una especie asexual cercana al género ascomiceto Epichloë (Tsai et al. 1994). Este último pertenece a la familia Clavicipitaceae, cuyas especies parásitas de plantas son conocidas por producir varios tipos de alcaloides tóxicos. Las plantas de $F$. arundinacea infectadas por $N$. coenophialum contienen alcaloides tóxicos (Lyons et al. 1986).

Existen reportes de la región central de Argentina donde, dentro de las gramíneas nativas conocidas como tóxicas para el ganado, se ha aislado el endófito fúngico Neotyphodium tembladerae Cabral \& White (Cabral et al. 1999) y se han determinado los alcaloides sintetizados por el simbionte, los que corresponderían a análogos de indol-diterpenos tremorgénicos (Miles et al. 1998, Benavente et al. 2008). 
En un estudio realizado por Bacon et al. (1977), se demostró que una serie de trastornos del ganado vacuno, hasta entonces asociados al consumo de pastos de $F$. arundinacea, se presentaban cuando las plantas estaban infectadas por el hongo $N$. coenophialum. Los síntomas de la toxicosis son diversos y van desde elevación de la temperatura corporal, inapetencia, aspereza y pérdida del brillo del pelo, a un número elevado de abortos y gangrenas en extremidades, orejas y cola (Bacon et al. 1986). Un síntoma más sutil, pero importante para la producción ganadera, es la reducción de la ganancia media diaria de peso en aproximadamente 50\% (Paterson et al. 1995).

Otra especie forrajera atacada por endofiticos del género Acremonium es el ballico perene (Lolium perene) ampliamente distribuído en el mundo. Este endofitico fue identificado por Latch et al. (1984) como Acremonium lolii. Fletcher y Harvey (1981), señalan una asociación entre este endofitico y los desórdenes nerviosos en ovejas. A partir de cultivos puros de $A$. lolii, han sido aislados alcaloides como la peramina, por lo cual este puede ser sintetizado en ausencia de la planta. Asimismo, se han encontrado compuestos neurotóxicos que corresponden a toxinas tremogénicas conocidas comúnmente como lolitremos (Galdames y Rojas 1996).

El lolitrem B es considerado el principal responsable del síndrome del temblor en ovejas (ryegrass staggers), ocasionando en los animales una reducción de su función neuromuscular, que provoca temblores que puede variar desde leves atrofias musculares hasta ataxia e incoordinación que puede llevar a la muerte (Fletcher y Harvey 1981).

Dentro de los efectos identificados por la presencia de $A$. lolii destaca que existe una correlación significativa entre la disminución de ganancia de peso y los niveles de alcaloide del endofitico (Fletcher 1993). En el ganado bovino el efecto del endofitico sobre la ganancia de peso ha sido más leve y está influenciado por la época del año (Cosgove et al. 1996).

Específicamente, Acremonium zeae es considerado endófito del maíz (Wicklow y Poling 2009), por lo cual no se descarta que esta especie pueda producir micotoxinas que puedan afectar la salud humana y animal. El objetivo de este trabajo fue determinar si $A$. zeae afecta el desarrollo de pollos de engorde.

\section{MATERIALES Y MÉTODOS}

\section{Colecta de mazorcas infectadas con $A$. zeae}

La colecta de granos de maíz infectados por $A$. zeae se realizó en la región de Los Tuxtlas, al sur del estado de Veracruz, México, en el ciclo otoño-invierno de 2009. Debido a su topografía irregular, las altitudes de las localidades donde se colectaron las muestras de maíz fueron variables, de 450 a 600 msnm con clima cálido-húmedo y una precipitación anual de $4500 \mathrm{~mm}$. Se colectaron mazorcas de maíz con granos con síntomas parecidos a los causados por Acremonium zeae (sin. Cephalosporium acremonium).

\section{Aislamiento del hongo}

Granos de maíz con síntomas de pudrición por $A$. zeae se desinfestaron por inmersión en hipoclorito de sodio al 3\% durante dos minutos y se enjuagaron en dos ocasiones en agua destilada estéril para eliminar el exceso de hipoclorito de sodio por otros dos minutos, finalmente se colocaron en toallas de papel estériles para eliminar el exceso de humedad. En condiciones asépticas, 400 de estos granos se distribuyeron en 20 cajas Petri con papel absorbente húmedo en el fondo a manera de cámara húmeda. Las cajas se colocaron a temperatura ambiente por $72 \mathrm{~h}$, para favorecer el crecimiento micelial del hongo. Del micelio obtenido, se prepararon suspenciones conidiales de las cuales se tomaron $100 \mu 1$ ( 25 conidios $/ \mu 1)$ para depositarse en cajas Petri con agua-agar. De los cultivos monospóricos desarrollados se tomaron fragmentos del medio con micelio y se transfirieron a cajas Petri con papa-dextrosaagar (PDA), para incrementar el crecimiento del hongo. Posteriormente se aumentó el hongo utilizando $40 \mathrm{~kg}$ de avena entera estéril como sustrato (Tuite 1969).

\section{Identificación taxonómica y molecular del hongo}

La identificación taxonómica se realizó a nivel de género con las claves de Barnett y Hunter (1998). En aislamientos de diez días de edad se realizaron preparaciones temporales de micelio, conidióforos y conidios. De las estructuras se registró la forma, color, posición de conidióforo y tamaño de conidios. 
De los aislamientos monospóricos en PDA se obtuvo micelio para la extracción de ADN de acuerdo al protocolo de CTAB 3\% con modificaciones (Sambrook et al. 1989). El micelio se depositó en un tubo Eppendorf frío etiquetado, al que se agregó $600 \mu \mathrm{l}$ de CTAB a $60^{\circ} \mathrm{C}$ y se incubó a $60^{\circ} \mathrm{C}$ por una hora. Se adicionaron $600 \mu \mathrm{l}$ de cloroformo-alcohol isoamílico (24:1) y se centrifugó a $10000 \mathrm{rpm}$ por ocho minutos. La fase acuosa se recuperó en un tubo Eppendorf al que se adicionaron $600 \mu \mathrm{l}$ de isopropanol frío, se incubó a $-20^{\circ} \mathrm{C}$ por una hora.

Después de ese periodo se centrifugó a 8500 rpm por ocho minutos, se eliminó el sobrenadante y la pastilla (hebras de ADN) se lavó dos veces con etanol al $70 \%$. La suspensión se centrifugó nuevamente a $10000 \mathrm{rpm}$ por $8 \mathrm{~min}$., eliminando el sobrenadante. Finalmente se recuperó el ADN en $100 \mu 1$ de agua destilada estéril, se evaluó la calidad por electroforesis en gel de agarosa (Agarose Ultra Pure) al $1 \%$ y se cuantificó en un espectrofotómetro.

Para la amplificación de las regiones internas ITS4 y ITS5 se usaron los iniciadores universales ITS4 (5' - TCC TCC GCT TAT TGA TAT GC - 3') e ITS5 (5'- GGA AGT AAA GTC GTA ACA AGG - 3') (Gomes et al., 2002). La mezcla de la reacción fue: Buffer 1x $(2,5 \mu \mathrm{L}), \mathrm{MgCl}_{2} 35 \mathrm{mM}(2,0 \mu \mathrm{L})$, dNTP's $2,5 \mathrm{mM}(1 \mu \mathrm{L})$, ITS 4 a $10 \mathrm{pm}(2 \mu \mathrm{L})$, ITS 5 a $10 \mathrm{pm}$ $(2 \mu \mathrm{L})$, Taq polimerasa $1 \mathrm{U}(0,2 \mu \mathrm{L})$, DNA $80 \mathrm{ng}(2$ $\mu \mathrm{L}$ ), agua libre de nucleasas (completada para $25 \mu \mathrm{L}$ por reacción).

La reacción se efectuó en un termociclador (Modelo PCR System 2400) con el siguiente programa: predesnaturalización de $95^{\circ} \mathrm{C}$ por dos minutos; treinta ciclos de desnaturalización de $95^{\circ} \mathrm{C}$ por un minuto; alineamiento a $55^{\circ} \mathrm{C}$ por $30 \mathrm{seg}$; preextensión de $72^{\circ} \mathrm{C}$ por dos minutos, y una extensión final de $72^{\circ} \mathrm{C}$ por diez minutos. El producto de PCR se analizó por electroforesis en gel de agarosa al $1 \%$ y tiñó con bromuro de etidio. Posteriormente las muestras se enviaron a secuenciar sin purificar al Instituto de Biotecnología de la Universidad Nacional Autónoma de México. La comparación de secuencias se realizó en GenBank alineando con $A$. zeae con el número de acceso HQ402899.

\section{Incremento del hongo en sustrato de avena}

La decisión de contaminar avena en lugar de maíz se debió a que el maíz es un grano con una testa más dura por lo cual su inoculación resultaba casi imposible ya que se requería más tiempo para logran un crecimiento considerable, tiempo en el cual también se desarrollaban otros patógenos que no eran de interés en esta investigación.

Para incrementar la cantidad de hongo, se inocularon $40 \mathrm{~kg}$ de avena en grano como sustrato previamente esterilizados (Tuite 1969). La avena entera se lavó tres veces en agua corriente para retirar impurezas, se sumergió en agua por 16 horas y después de un lavado final con agua, se colocaron $500 \mathrm{~g}$ de avena en doble bolsa de polipapel para esterilizarse por dos horas a 15 psi. Después de dejarse enfriar la bolsa a temperatura ambiente, se colocó un fragmento de un centímetro de diámetro del medio de cultivo con crecimiento micelial de A. zeae sobre el sustrato de avena en condiciones estériles. Diariamente durante cinco semanas el contenido de la bolsa se agitó para mejorar la distribución y desarrollo micelial en el sustrato.

\section{Elaboración de dietas}

Una vez que la avena inoculada mostró buen desarrollo micelial del hongo, se elaboraron cinco dietas con las que se alimentó a los pollos de los diferentes tratamientos, estas se probaron siguiendo un diseño experimental completamente al azar. Cada tratamiento se preparó con mezclas de grano entero de avena molida sana o contaminada con A. zeae añadiendo otros componentes como maíz sano, pasta de soya, carbonato de calcio, fosfato, vitaminas y minerales (Cuadro 1). Es importante mencionar que no se realizó una medición final de la cantidad de hongo en cada dieta puesto que en este trabajo el objetivo principal es determinar si la presencia de A. zeae tiene efectos negativos o no.

Para la elaboración de las dietas, se realizaron análisis previos en el Laboratorio de Nutrición Animal del Depto. de Zootecnia, en la Universidad Autónoma Chapingo, Texcoco, Estado de México. Se determinó la cantidad de proteína, en maíz $(7,76 \%)$, avena $(10,36 \%)$ y pasta de soya $(48 \%)$. Se elaboraron las dietas considerando los requerimientos de aminoácidos, energía y minerales para llenar las necesidades de los pollos en iniciación (Cuca et al. 2009).

\section{Establecimiento del ensayo para evaluar efecto de dieta}

La investigación fue realizada en el Colegio de Postgraduados, campus Montecillo en el municipio 
Cuadro 1. Composición de las dietas experimentales para pollos de engorde durante la etapa de cero a tres semanas, elaboradas con diferentes porcentajes de avena contaminada con A. zeae. Montecillo, Estado de México, México. Octubre, 2010.

\begin{tabular}{lccccc}
\hline & \multicolumn{5}{c}{ Tratamientos } \\
\cline { 2 - 5 } & $\mathbf{T 1}$ & $\mathbf{T 2}$ & $\mathbf{T 3}$ & $\mathbf{T 4}$ & $\mathbf{T 5}$ \\
Ingredientes (\%) & $\mathbf{0 / 1 0 0}$ & $\mathbf{2 5 / 7 5}$ & $\mathbf{5 0 / 5 0}$ & $\mathbf{7 5 / 2 5}$ & $\mathbf{1 0 0 / 0}$ \\
\hline Maíz & 54,00 & 40,5 & 26,77 & 13,00 & 0,00 \\
Avena contaminada & 0,00 & 13,00 & 26,77 & 40,05 & 54,00 \\
Pasta de soya & 39,00 & 38,40 & 38,00 & 37,00 & 36,00 \\
Arena & 1,60 & 1,50 & 1,60 & 1,30 & 0,60 \\
Aceite crudo de soya & 1,70 & 2,90 & 3,70 & 5,10 & 5,80 \\
DL-Metionina & 0,16 & 0,15 & 0,15 & 0,15 & 0,16 \\
CaCO3 (38) & 1,60 & 1,60 & 1,50 & 1,60 & 1,60 \\
Fosfato dicálcico (18/21)* & 1,35 & 1,30 & 1,30 & 1,20 & 1,20 \\
Premezcla vitamínica** & 0,12 & 0,12 & 0,12 & 0,12 & 0,12 \\
Premezcla mineral*** & 0,13 & 0,13 & 0,13 & 0,13 & 0,13 \\
Sal & 0,35 & 0,35 & 0,35 & 0,35 & 0,35 \\
Total & 100,00 & 100,00 & 100,00 & 100,00 & 100,00 \\
Análisis calculado & & & & 290 \\
Energía metabolizable (Kcal/kg) & 2934,77 & 2922,82 & 2934,69 & 2927,66 & 2929,33 \\
Proteína cruda (\%) & 22,27 & 22,42 & 22,25 & 22,25 & 22,22 \\
Calcio (\%) & 0,96 & 0,94 & 0,97 & 0,97 & 0,97 \\
Fósforo disponible (\%) & 0,44 & 0,45 & 0,44 & 0,45 & 0,44 \\
\hline
\end{tabular}

$* 18 \%=$ fósforo y $21 \%$ = calcio

** Aporta por kilogramo de alimento: vitamina A, 9000 UI; vitamina $\mathrm{D}_{3}, 2500$ UI; vitamina $\mathrm{E}, 20 \mathrm{UI}$; vitamina $\mathrm{K}$, 3,0 mg; vitamina $\mathrm{B}_{2}, 8,0 \mathrm{mg}$; vitamina $\mathrm{B}_{12}, 0,015 \mathrm{mg}$; ácido pantoténico, $10 \mathrm{mg}$; niacina, $40 \mathrm{mg}$; ácido fólico, 0,5 mg; colina, $300 \mathrm{mg}$; biótina, 0,055 mg; tiamina, 2,0 mg.

***Aporta por kilogramo de alimento: hierro, 65,0 mg; zinc, $100 \mathrm{mg}$; manganeso, $100 \mathrm{mg}$; cobre, 9,0 mg; selenio, $0,3 \mathrm{mg}$; yodo, $0,9 \mathrm{mg}$.

T1, 0\% avena contaminada - $100 \%$ maíz; T2, 25\% avena contaminada - 75\% maíz; T3, 50\% avena contaminada - 50\% maíz; T4, 75\% avena contaminada - 25\% maíz; T5, 100\% avena contaminada - 0\% maíz.

de Texcoco, Estado de México. Se adquirieron 125 pollitos de la línea Ross recién nacidos en la empresa Reproductora Unión Tepexpan, del Estado de México. Los animales se pesaron individualmente y se distribuyeron aleatoriamente en cinco repeticiones cada una con cinco pollos por tratamiento (T). Durante el ensayo, los pollos se mantuvieron en jaulas eléctricas en batería con temperatura controlada, asimismo se midió la temperatura y humedad relativa del ambiente con ayuda de un data logger. La ganancia de peso y consumo de alimento se registró en gramos en tres ocasiones.

\section{RESULTADOS Y DISCUSIÓN}

\section{Identificación del hongo causante de la pudrición en mazorca}

De los granos de maíz con síntomas de pudrición colectados en regiones productoras de maíz del estado de Veracruz, se obtuvieron colonias con un crecimiento moderado y micelio algodonoso blanco, el cual se tornó de color salmón tenue después de cuatro días de crecimiento en PDA (Figura 1 A). Las colonias no desarrollaron crecimiento micelial 

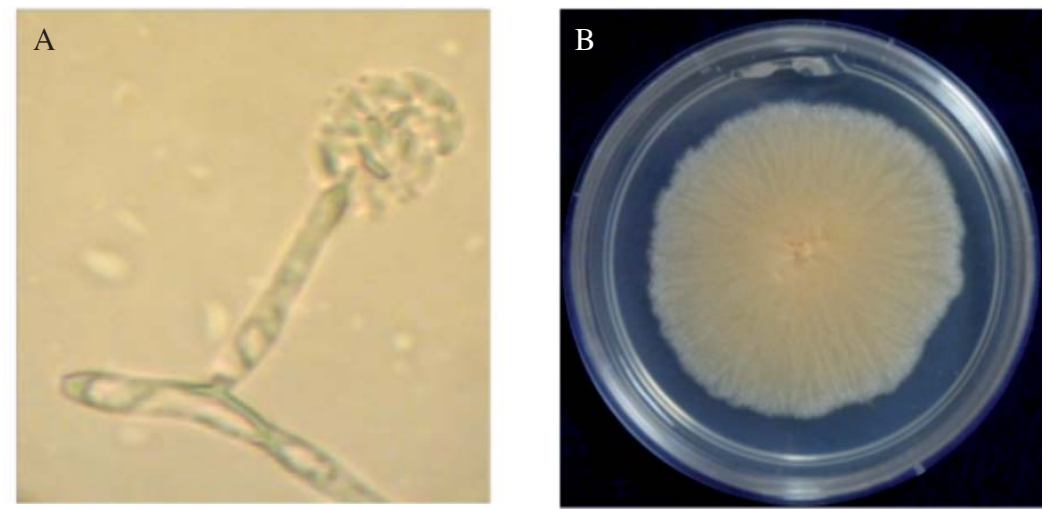

Figura 1. A) Conidióforo de Acremonium zeae con conidios agrupado en cabezuela, formando un ángulo de $90^{\circ}$ entre el micelio y conidióforo, B) Cepa de Acremonium zeae de quince días de crecimiento en PDA a temperatura ambiente. Montecillo, Estado de México, México. Agosto 2010.

aéreo pero si abundante micelio hialino acompañado de conidios unicelulares agrupados en cabezuela sobre un conidióforo característico de las especies de Acremonium (sin. Cephalosporium) (Barnett y Hunter 1998) (Figura 1 B).

La secuencia del producto de PCR de los aislamientos monospóricos se alineó con las secuencias de Acremonium zeae del Banco de Genes del NCBI. El índice de similaridad de nucleótidos entre la secuencia de los cultivos monospóricos, con número de acceso HQ402899 de este estudio, respecto al de la especie alineada en el Banco de genes fue de 99\%. Confirmando que el agente causal de la pudrición de granos de maíz en las regiones productoras de maíz muestreadas del estado de Veracruz es A. zeae.

Los granos de avena con un crecimiento micelial abundante se obtuvieron en un periodo de seis semanas a temperatura ambiente.

\section{Evaluación del efecto de Acremonium zeae en la ganancia de peso de pollos de engorda en iniciación}

En el área donde se estableció el experimento, se registró una temperatura media de $22,8^{\circ} \mathrm{C}$ y humedad relativa del 59,83\%. Para el análisis de los datos se probaron las tres estructuras de covarianza antes señaladas haciendo uso del PROC MIXED, los criterios AIC y SBC obtenidos para cada modelo de estructura se presentan en el Cuadro 2. De acuerdo
Cuadro 2. Criterios de información de Akaike (AIC) y Bayesiano de Schwarz(SBC) según la estructura de covarianzas. Montecillo, Edo. de México. Agosto, 2010 .

\begin{tabular}{lcc}
\hline Estructura & \multicolumn{2}{c}{ Criterios } \\
\cline { 2 - 3 } & AIC & SBC \\
\hline Simétrica Compuesta & 802,6 & 823,3 \\
CS & & \\
No estructurada UN & 722,8 & 749,6 \\
Autoregresiva AR 1 & 795,2 & 815,9 \\
\hline
\end{tabular}

a estos criterios se seleccionó como estructura de covarianza más adecuada para los datos de ganancia de peso la covarianza sin estructura (UN).

Con un nivel de significancia del 5\%, la interacción de los tratamientos y el tiempo influyeron en la ganancia de peso (Cuadro 3). El efecto del tratamiento también fue significativo a un nivel de significancia del $5 \%$ es decir, que la composición de las dietas influyó en la ganancia de peso de los pollos. Así mismo se muestra que existió diferencia entre cada uno de los periodos de evaluación con el mismo nivel de significancia.

Adicionalmente se construyó una gráfica de ganancia de peso promedio para cada combinación de tratamiento y evaluación (Figura 2) en la cual se muestra que existieron diferencias en la ganancia de peso 
Cuadro 3. Consumo de alimento de pollos alimentados con diferentes porcentajes de avena contaminada con Acremonium zeae durante tres semanas. Montecillo, Estado de México. Noviembre 2010.

\begin{tabular}{cccc}
\hline Tratamientos & $\mathbf{7}$ días $(\mathbf{g})$ & $\mathbf{1 4}$ días $(\mathbf{g})$ & $\mathbf{2 1 ~ d i ́ a s ~}(\mathbf{g})$ \\
\hline T1 & $765 \mathrm{a}$ & $1686 \mathrm{a}$ & $3589 \mathrm{a}$ \\
T2 & $771 \mathrm{a}$ & $1761 \mathrm{a}$ & $3481 \mathrm{a}$ \\
T3 & $829 \mathrm{a}$ & $1451 \mathrm{~b}$ & $1345 \mathrm{~b}$ \\
T4 & $770 \mathrm{a}$ & $1338 \mathrm{~b}$ & $1230 \mathrm{bc}$ \\
T5 & $829 \mathrm{a}$ & $1254 \mathrm{~b}$ & $1083 \mathrm{c}$ \\
\hline
\end{tabular}

Medias con la misma letra no son diferentes estadísticamente (DMS, $\alpha=0,05)$.

T1,0\% avena contaminada - 100\% maíz; T2, 25\% avena contaminada - 75\% maíz; T3, 50\% avena contaminada - 50\% maíz; T4, $75 \%$ avena contaminada - 25\% maíz; T5, $100 \%$ avena contaminada - 0\% maíz.

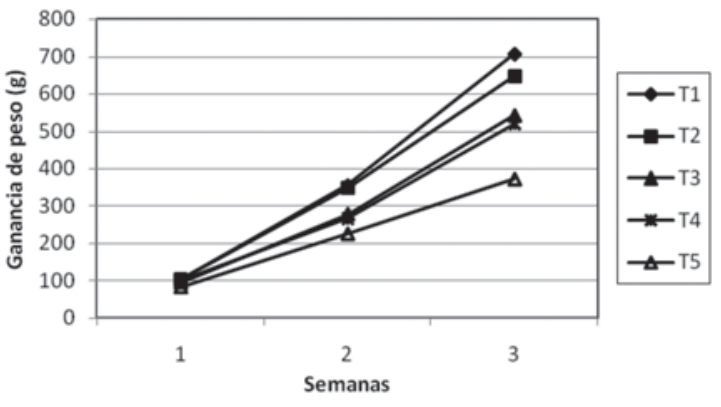

Figura 2. Ganancia de peso promedio en pollos de engorde para cada combinación de tratamiento (con o sin avena contaminada con A. zeae). Montecillo, Edo. de México. Agosto, 2010.

para cada una de las evaluaciones semanas. Hubo una ganancia de peso entre todos los tratamientos durante la primera semana de evaluación, este comportamiento no se mantuvo así para la segunda evaluación ya que existe una ganancia de peso muy similar entre los tratamientos T1 y T2 y T3 y T4, no siendo el caso del T5 en el que se observa una menor ganancia de peso respecto al testigo y el resto de los tratamientos. Para la tercera evaluación la diferencia en la ganancia de peso en cada uno de los tratamientos se hace más evidente; aunque se conserva la misma tendencia.

\section{Evaluación del efecto de Acremonium zeae en el con- sumo de alimento de pollos de engorde en iniciación}

Después de realizar las tres evaluaciones semanales, nuevamente se realizó un análisis estadístico de los datos de consumo de alimento en el cual se evaluaron las tres estructuras de covarianza antes señaladas haciendo uso del PROC MIXED, los criterios AIC y SBC obtenidos para cada modelo de estructura se presentan en el Cuadro 4. De acuerdo a estos criterios se seleccionó como estructura de covarianza más adecuada para los datos de ganancia de peso la estructura simétrica compuesta (CS).

Los valores obtenidos del análisis de varianza demuestran que el efecto de la interacción fue significativo a un nivel de significancia del $5 \%$ esto es, la interacción de los tratamientos y el tiempo influyeron en el consumo de alimento. El efecto de los tratamientos también fue significativo a un nivel de significancia del $5 \%$ es decir, que la composición de las dietas influyó en la cantidad de alimento consumido por los pollos.

Así mismo se muestra que existe diferencia entre cada uno de los periodos de evaluación con el mismo nivel de significancia.

Se construyó una gráfica para analizar el consumo de alimento promedio para cada combinación tratamiento y evaluación (Figura 3) con la cual se puede observar que existió diferente consumo de alimento para cada momento evaluado.

Se puede observar que además un consumo similar entre los tratamientos al momento de la primera evaluación, por lo que se puede concluir que es difícil apreciar el efecto de las diferentes dietas proporcionadas como alimento para pollos a siete días de su consumo. Para la siguiente evaluación (semana 2) el consumo de alimento se incrementó en todos los tratamientos, apreciándose una diferencia de T4 y T5 con 
Cuadro 4. Criterios de información de Akaike (AIC) y Bayesiano de Schwarz(SBC) según la estructura de covarianzas. Montecillo, Edo, de México. 2010.

\begin{tabular}{lcc}
\hline \multirow{2}{*}{ ESTRUCTURA } & \multicolumn{2}{c}{ Criterios } \\
\cline { 2 - 3 } & AIC & SBC \\
\hline Simétrica compuesta CS & 720,9 & 740,4 \\
No estructurada & 724,7 & 751,5 \\
Autoregresiva & 722,1 & 742,9 \\
\hline
\end{tabular}

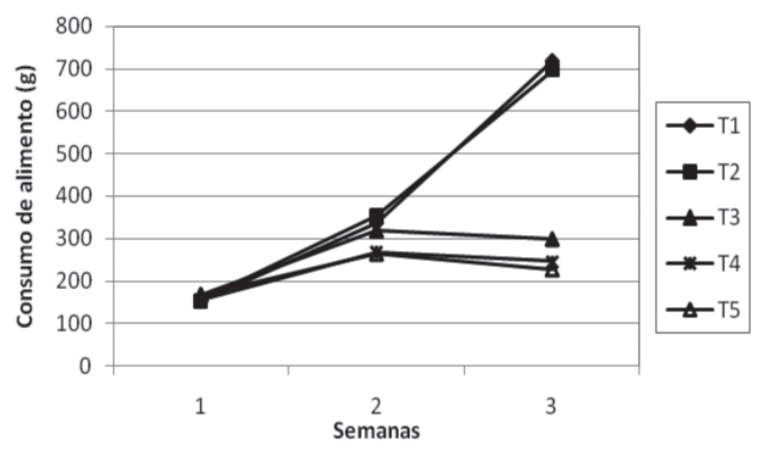

Figura 3. Ganancia de peso promedio en pollos de engorde para cada combinación de tratamiento (con y sin avena contaminada con A. zeae). Montecillo, Edo. de México. 2010.

respecto al resto, estos a pesar de haber incrementado el consumo difieren significativamente de los tratamientos T1, T2 y T3. Las dietas elaboradas con una proporción $75 \%$ avena contaminada- $25 \%$ maíz o más tuvieron un efecto en el consumo de alimento. En la tercera evaluación se observó una clara diferencia en el consumo de alimento para cada tratamiento, para los T1 y T2 este aumentó significativamente mientras que para T3, T4 y T5 el consumo de alimento se redujo respecto al de la segunda evaluación.

Después de la tercera semana, la reducción en el consumo de alimento con los tratamientos T3, T4 y T5 fue de $58 \%, 66 \%$ y $68 \%$ respecto al testigo. En este periodo se observa que los pollos del tratamiento T5, registraron el menor consumo de alimento, lo cual se atribuye a que esta dieta estuvo elaborada con el mayor porcentaje de avena contaminada. En contraste, con el tratamiento T2 no se encontró diferencia significativa en el consumo de alimento respecto al tratamiento testigo $\mathrm{T} 1$, se puede observar que esta cantidad de avena contaminada es aun tolerable por el ave.

El coeficiente de correlación muestra que las variables peso y consumo de alimento tuvieron una correlación positiva, en la que, a altos valores de peso le correspondieron altos valores de consumo de alimento. Con una probabilidad de error $<0,0001$, se confirma que el coeficiente de correlación de Pearson $(r=0,8173)$ fue estadísticamente diferente a cero.

Los resultados anteriores confirman que la presencia de especies del hongo Acremonium en el alimento puede resultar en cuadros de intoxicación animal como lo reportaron previamente Towers y Siegel (1993) y Galdames (1995). En aves, Whitlow y Hagler (2005) y Cuca et al. (2009) reportan la reducción de consumo de alimento y peso como uno de los principales efectos ocasionados por la presencia de micotoxinas en el alimento, tal como puede observarse en las Figuras 2 y 3 . Hasta ahora no se ha demostrado que Acremonium zeae produzca algún metabolito que pueda actuar como micotoxina; sin embargo, esta hipótesis no se descarta ya que en los parámetros analizados en la presente investigación, peso y consumo de alimento, mostraron efectos negativos en el crecimiento de pollos por la presencia de este hongo en una dieta balanceada para pollos de engorde de iniciación.

La presencia de Acremonium zeae en la dieta afectó el incremento de peso y consumo de alimento en pollos de engorde, efecto que se hace más evidente a partir de la segunda semana de alimentación con una composición de dieta elaborada con un mínimo de $50 \%$ de avena contaminada con el hongo.

\section{AGRADECIMIENTOS}

Al CONACYT por el apoyo económico a través de la beca de maestría, con número de becario 294360.

\section{LITERATURA CITADA}

Bacon, CW; Lyons, PC; Porter, JK; Robbins, JD. 1986. Ergot toxicity from endophyte-infected grasses: a review. Agron. J. 78, 106-116. 
Bacon, CW; Porter, JK; Robbins, JD; Luttrell, ES. 1977. Ephichloë typhina from toxic tall fescue grasses. Appl. Environ. Microbiol. 34:576-581.

Barnett, O; Hunter, B. 1998. Illustrated genera of imperfect fungi. Burg. Publ. Co. Minneapolis, MN. USA. 218 p.

Benavente, AC; Kurina, SM; Lugo, AM. 2008. Micofilas, endófitos fúngicos y alcaloides en poblaciones de Melica stuckertii (Poaceae) del Centro de Argentina. Bol. Soc. Argent. Bot. 43 (3-4):189-195.

Cabral, D; Cafaro, MJ; Reddy, PV; Lugo, MA; White, JF. 1999. Evidence supporting the ocurrence of a new species of endophyte in some South American grasses. Mycologia 91:315-325.

Carvajal, M; De León, C. 2010. Toxinas importantes de los hongos Aspergillus (aflatoxinas), Fusarium (fumonisina), Diplodia (diplodiatoxina) y diplodiol en maíz. In El cultivo de maíz, Temas Selectos, Vol II. Edit. Mundi-Prensa. p. 36-47.

CAST (Council for Agricultural Sciense and Technology). 2003. Mycotoxins: Risk in plant, animal and human systems. Report No.139. Ames, IO. USA. p. 4-5.

Chapman, GP. 1996. Grass diversity. In The Biology of grasses. CAB Internatl. Oxon, UK. p. 14-35.

CIMMYT (Centro Internacional de Mejoramiento de Maíz y Trigo). 2004. Enfermedades del maíz. Una guía para su identificación en el campo. El Batán, México 4 ed. $118 \mathrm{p}$.

Cosgove, G; Anderson, C; Berquist, T. 1996. Fungal endophyte effects on intake, health and live weight gain of grazind cattle. Proc. New Zealand Grassland Assoc. 57:43-48.

Cuca G, M; Ávila G, E; Pro M, A. 2009. Alimentación de las aves. Univ. Autónoma Chapingo, Dpto. de Zootecnia. México. 276 p.

CIMMYT (Centro Internacional de Mejoramiento de Maíz y Trigo). 2004. Enfermedades del maíz. Una guía para su identificación en el campo. El Batán, México 4 ed. $118 \mathrm{p}$.

Duarte V, S; Villamil J, L. 2006. Micotoxinas en la salud pública. Revista Salud Pública. Supl. 8:129-135.

FAO. 2008. FAOSTAT. Consultado 8 Sept. 2010. Disponible en http://faostat.fao.org

Fletcher, L. 1993. Grazing ryegrass/endophyte associations and their effect on animal health and performance. Proc. $2^{\text {nd }}$ Internatl. Symp. on Acremonium/grass interactions. Ed.Hume, Lech and Easton. Palmerston North, N.Z. p. 115-120.
Fletcher, LR; Harvey, IC. 1981. An association of a Lolium endophyte with ryegrass staggers. New Zealand Vet. J. 29:185-186.

Galdames, R. 1995. El hongo endofitico de la festuca, Acremonium coenophialum Morgan-Jones \& Gams, y su incidencia en el sur de chile. Agricultura Técnica de Chile 55(1):67-70.

Galdames, GR; Rojas, GC. 1996. Hongos endófitos en gramíneas forrajeras y su asociación con la producción animal en praderas de Chile. Inst. Invest. Agrop. Consultado 8 set. 2010. Disponible en http://www.inia.cl/ medios/biblioteca/libros/NR30980.pdf

Glenn, AE; Bacon, CW; Price, R; Hanlin, RT. 1996. Molecular phylogeny of Acremonium and its taxonomic implications. Mycologia 88:369-383.

Gomes, E; Kasuya, MC; De Barros, E; Borges, A; Araujo, E. 2002. Polymorphism in the internal transcribed spacer (ITS) of the ribosomal DNA of 26 isolates of ectomycorrhizal fungi. Genet. Molec. Biol. 25:477-483.

Gros, EG; Pomilio, AB; Seldes, AM; Burton, G. 1985. Introducción al estudio de los productos naturales. Sria. Gral. Organización de Estados Americanos, Washington DC. 146 p.

Latch, G. C. M; Christensen, M. J; Samuels, G. J. 1984. Fice endophytes of Lolium and Festuca in New Zealand. Mycotaxon. 20(2):535-550.

Lyons, PC; Plattner, RD; Bacon, CW. 1986. Occurrence of peptide and clavine ergot alkaloids in tall fescue grass. Science 232:487-489.

Miles, CO; Di Menna, ME; Jacobs, SW; Garthwaite, I; Lane, GA; Prestidge, RA; Marshall, SL; Wilkinson, HH; Schardl, CL; Ball, OJP; Latch, GCM. 1998. Endophytic fungi in indigenous australasian grasses associated with toxicity to livestock. Appl. Environ. Microbiol. 64:601-606.

Morgan-Jones, G; Gams, W. 1982. Notes on Hyphomycetes, XLI. An endophyte of Festuca arundinacea and the anamorph of Epichloë typhina, new taxa in one of two new sections of Acremonium. Mycotaxon 15:311-318.

Paterson, J; Forcherio, C; Larson, B; Samford, M; Kerley, M. 1995. The effects of fescue toxicosis on beef cattle productivity. J. Anim. Sci. 73:889-898.

Sambrook, J; Fritsch E; Maniatis, T. 1989. Molecular cloning. A laboratory manual. Cold Spring Harbor Lab. Press. New York, E. U. A.

SAS® (Statistical Analysis System). 2002. Software Versión 9.0 
Scott, BD; Young, C; Mc Millan, L. 1999. Molecular biology of Epichloe endophyte toxin biosintesis. Ryegrass endophyte: an essencial New Zealand Simbiosis. Grassland Res. Pract. Series 7:77-83.

Siegel, MR; Latch, GC; Johnson, MC. 1985. Acremonium fungal endophytes of tall fescue and perennial rygrass: significance and control. Plant Disease 69(2):179-183.

Spiering, MJ; Lane, GA; Christensen, MJ; Schmid, J. 2005. Distribution of the dungal endophyte Neotyphodium lolii is not major determinat of the distribution of fungal alkaloids in Lolium perenne plants. Phytochemistry 66:195-202.

Towers, NR; Siegel, MR. 1993. Coping with mycotoxins that constrain animal production. In Grasslands for our world. M.J. Baker (ed) SIR Publi. Wellington, N. Zealand. p. 548-554.

Tsai, HF; Liu, JS; Staben, C; Christensen, MJ; Latch, GCM; Siegel, MR; Schardl, CL. 1994. Evolutionary diversification of fungal endophytes of tall fescue grass by hybridization with Epichloë species. USA 91:2542-2546.

Tuite, J. 1969. Plant pathological methods. Purdue University, IN. 239 p.

Whitlow, L; Hagler, W. 2005. Mycotoxins in dairy cattle: Occurrence, toxicity, prevention and treatment. Proc. Southwest Nutr. Conf. p. 124-138.

Wicklow, DT; Poling, SM. 2009. Antimicrobial activity of pyrrocidines from Acremonium zeae against endophytes and pathogens of maize. Phytopathology 99:109-115. 